\title{
Digresión y subversión del género policial en Estrella distante de Roberto Bolaño*
}

\author{
Digression and subversion of the crime fiction genre in \\ Roberto Bolaño's Estrella distante
}

\begin{abstract}
María Paz Oliver
Katholieke Universiteit Leuven. Lovaina, Bélgica

maria.oliver@student.kuleuven.be

\section{RESUMEN}

Considerando los vínculos de la obra de Roberto Bolaño con la narrativa policial, este artículo se propone analizar la relación entre el uso de la digresión y la desestructuración del género policial en la novela Estrella distante. La digresión como recurso destinado a interrumpir el hilo narrativo no sólo tendería a desviar y fragmentar la historia, sino también a modificar el enigma policial. De este modo, nos interesa estudiar cómo a través del constante desplazamiento del enigma la digresión opera como una estrategia subversiva que quiebra la estructura e impide una lectura apegada al género.
\end{abstract}

Palabras clave: Loiterature, crimen, enigma, errabundia.

\section{ABSTRACT}

Considering the relevance of crime narrative in Roberto Bolaño's work, this article aim at exploring the relation between the use of digression and the deconstruction of the crime fiction genre. Digression as a technique aimed at interrupting the narration not only tends to deflect and fragment the story, but also to change the notion of mystery.

* El presente trabajo se inscribe en el marco de una investigación doctoral financiada por Conicyt en torno al uso de la digresión en la narrativa latinoamericana contemporánea, que se realiza en la Facultad de Artes de la Universidad Católica de Lovaina (K.U. Leuven). 
Thus, we propose to study how digression operates through a constant shifting of the mystery as a subversive strategy which breaks the structure and impedes a canonical reading of the genre.

Keywords: Loiterature, crime, mystery, errancy.

Recibido: 23.12.2011. Aceptado: 27.02.2012.

I ejos del creciente entusiasmo por su obra y en lo que sería uno de los primeros trabajos sobre el relato policial en las novelas de Roberto Bolaño, Ezequiel De Rosso (2002) propuso que sus obras están escritas sobre una matriz genérica en sintonía con el policial, pero que de todas formas no satisface sus premisas básicas. Y así, una novela como Estrella distante (1996a) se inscribiría dentro de un nuevo tipo de ficción cuyos juegos con elementos típicamente policiales tenderían a desafiar toda clasificación genérica $(140,141)$. Una ficción donde abundarían los espejos y las puestas en escena, y que de paso también podríamos leer como representativa del relato posmoderno de las dos últimas décadas no sólo latinoamericano ${ }^{1}$, en Bolaño se traduce en un corpus híbrido cuyos rasgos policiales se desnaturalizan y alejan de la rigidez propia de este género. Por eso, lo que particularmente constituye tan sólo un guiño o un referente en La pista de hielo (1993), La literatura nazi en América (1996b), Los detectives salvajes (1998), Monsieur Pain (1999) y 2666 (2004), en Estrella distante pasa a formar parte de una estructura que intenta alterar y reescribir el modelo heredado del canon policial -sobre todo aquel derivado del relato de enigma de Poe- a través de una escritura digresiva que finalmente termina por convertirse en una marca de su narrativa.

Considerando el diálogo que Bolaño desarrolla en la novela con el género policial, y que en líneas generales ya ha sido planteado en otros estudios sobre su obra ${ }^{2}$, este artículo pretende abordar el uso de la digresión en rela-

${ }^{1}$ Pensamos en Ricardo Piglia, Rodrigo Rey Rosa, Horacio Castellanos-Moya, Rodrigo Fresán, del lado latinoamericano; o en Javier Cercas y Enrique Vila-Matas, en España; todos unidos por una cierta sensibilidad y admiración por la tradición del género policial y, en general, por los géneros catalogados como menores, que también los acerca a la obra de autores norteamericanos como Thomas Pynchon, Philip K. Dick o Don De Lillo (Tréllez Paz, 2005: 148).

${ }^{2}$ Sobre el género policial en la obra de Bolaño véase: "La proyección del secreto. Imagen y enigma en la obra de Roberto Bolaño" de Joaquín Manzi (2005); "El lector como detective en la narrativa de Bolaño" de Diego Tréllez Paz (2005); "La narrativa policial como género de la modernidad: La pista de Bolaño" de Magda Sepúlveda (2003); "Estrella distante: crimen y poesía" de Horacio Simunovic (2006); "La desautomatización del género policíaco en 'William Burns', de 
ción con la desestructuración del género o la imposibilidad de una lectura apegada al canon policial. De este modo, nos interesa examinar, por una parte, de qué modo esta estrategia destinada a desviar la narración implicaría un acercamiento subversivo al género policial y, por otra, cómo se convierte en una técnica que desplaza constantemente el enigma a través de la creación de historias que funcionan como ampliaciones o reflejos de otras.

Un rasgo distintivo de todo relato policial es una estructura u organización narrativa específica encaminada a resolver un enigma. Visto así, la clave para identificar el nivel de participación de una obra dentro de los límites de un género estaría en cómo cada una de sus partes tiende a la resolución de un enigma (Barthes, 2004: 14, 15). Esta figura, que para Ricardo Piglia remite a "lo que no se comprende, lo que está encerrado; el adentro puro" (2005: 85), contiene en última instancia el crimen que justifica todo el relato y que define su carácter policial. En Estrella distante, a primera vista el enigma sobre el que girará toda la narración de Bolaño, y que se apoya en el testimonio de Arturo $\mathrm{B}^{3}$, está centrado en Carlos Wieder, un poeta asesino que el narrador conoce en el taller de poesía de Diego Soto -al que también asistirían sus primeras víctimas, las hermanas Garmendia-, entre 1971 y 1972 en Concepción y que, por entonces, antes del golpe de Estado, se hacía llamar Alberto Ruiz-Tagle 4 . Para verificar por qué las expectativas de una lectura policial prontamente son diluidas por la utilización de la digresión como recurso subversivo, será necesario analizar cuál es su impacto sobre cada una de las partes que componen la estructura de un relato policial, a saber: el enigma, los indicios, el detective y la investigación (Hoveyda, 1967: 11-14).

Si consideramos que la digresión es un recurso narrativo que se encarga de suspender momentáneamente el hilo de una historia, probablemente podríamos reconocerla como un aspecto esencial de todo relato, y que ya desde

Roberto Bolaño" de Juan Antonio López Rivera (2005); "Bolaño y las relecturas de la novela negra: La pista de hielo" de Mirian Pino (2006).

${ }^{3}$ Como Bolaño advierte en el prefacio, Estrella distante se desprende del penúltimo capítulo de La literatura nazi en América (1996), "Ramírez Hoffman, el infame", historia que a su vez le habría contado Arturo B. Las diferencias, aparte de la extensión, están sobre todo en los detalles (en la primera versión hay dos menciones explícitas a Bolaño como personaje) y en la modificación de algunos nombres, por ejemplo, Ramírez Hoffman en la novela será Carlos Wieder. Siguiendo el juego con los dobles, como sucede también en Los detectives salvajes, Amuleto, "El gusano", "Detectives" y 2666, las coincidencias sobre todo biográficas explican que este Arturo B sea leído como el alter ego del propio Bolaño (Manzoni, 2002: 40).

${ }^{4}$ Recordemos que Alberto Ruiz-Tagle era el seudónimo que utilizaba Carlos Wieder en su juventud. Esta variación en los nombres extiende así la ilusión 'del otro' como recurso formal y argumental (Manzoni, 2002: 41), pues lo que Carlos Wieder esconde al cambiar su nombre no es sólo su identidad, sino también su pasado y la posibilidad de ser reconocido. 
la retórica clásica constituye una de las partes del discurso (Santovetti, 2007: $17)^{5}$. Sin embargo, en un sentido más amplio y posmoderno, para Ross Chambers una literatura que hace de la digresión una forma de concebir y componer la ficción entiende en esta idea del desvío una práctica desestabilizadora, cuyos intentos por interrumpir la historia y, en última instancia, hacerla inaccesible, son también una forma de atentar contra un orden o un modelo de relato convencional:

Digression, then, is a discursive 'slide' or 'slippage' along a line of continuity that links one context and its other, so that the new position one reaches is both linked with the first and discontinuous with it [...] digression is thus readily condemned, from the point of view of the maintenance of a certain cultural order, as a pente facile or slippery slope (1971: 12) ${ }^{6}$.

La introducción del desvío por medio de la digresión según Chambers provoca un quiebre en la cohesión del relato que, aunque en un principio pueda ser leído como una relajación en el discurso - muchas veces ligada a un narrador tan dubitativo como obsesivo-, más bien terminaría por configurar una literatura que transforma los trayectos erráticos de la narración en un modo compositivo, y que Chambers denomina con el término loiterature. Un concepto que englobaría a aquellas obras unidas por un afán evasivo que, mediante la digresión, desafía ciertas reglas que el propio relato se impone -específicamente el apego a un cierto orden progresivo o la cohesión que la historia misma reclama (1971: 85)-, y que en particular aplica en la literatura francesa y anglosajona ${ }^{7}$. En Estrella distante, el uso de formas pro-

5 "Digresión es también (a lo que yo entiendo) el tratar extraordinariamente de cosa distinta del asunto, pero que tiene con él alguna relación” (Quintiliano, 1799: 245-246).

6 "La digresión es, entonces, un deslizamiento discursivo o desplazamiento a lo largo de una línea de continuidad que vincula un contexto a otro, de modo que la nueva posición a la que uno llega está a la vez vinculada con la primera y separada de ella [...] la digresión es, pues, fácilmente condenada desde el punto de vista del mantenimiento de un orden cultural determinado, como una pendiente fácil y resbaladiza”. La traducción es mía. En el caso particular de Estrella distante la asociación más directa será con el género policial pero, desde luego, si lo aplicásemos en el resto de su producción se lo podría relacionar con el testimonio o las formas autobiográficas que cruzan novelas como Los detectives salvajes (1998) o Nocturno de Chile (2000).

${ }^{7}$ El estudio de Chambers sobre este concepto lo extiende a autores como Xavier de Maistre, Samuel Beckett o Paul Auster, y lo relaciona además con la literatura de viaje, la poesía y el concepto de flâneur. Del autor véase: "The Artist as Performing Dog" (1971); "Messing around: gayness and loiterature in Alan Hollinghurst's The swimming-pool Library" (1993); "Strolling, Touring, Cruising: Counter-Disciplinary Narrative and the Loiterature of Travel" (1994); "On Inventing Unknownness. The Poetry of Disenchanted Reenchantment (Leopardi, Baudelaire, Rimbaud, Justice)" (2008). 
pias del género policial da paso a una nueva manera de trabajar el crimen, que permite leer la novela como un ejercicio que transgrede el paradigma policial y, en definitiva, como un caso apócrifo del género.

En las primeras páginas sólo en apariencia se plantea el enigma como un posible móvil desde el cual se iniciará la investigación emprendida por el narrador, Arturo B, Bibiano O'Ryan y, finalmente, Abel Romero: el asesinato que realiza Carlos Wieder de las hermanas Garmendia. Esa escena, descrita al final del primer capítulo de la novela, determina la configuración de un enigma en torno al descubrimiento de las razones que tuvo el criminal para cometer ese hecho y que, de acuerdo a las tres variantes más reconocibles del género, se ajusta a la forma del enigma denominado whydunit ${ }^{8}$, cuya premisa es que cuando "el criminal es conocido desde un comienzo, se asiste a la ejecución del delito y al proceso que sigue el detective para develar la verdad" (Lafforge y Rivera, 1996: 263). Así, conocido el criminal, la estructura de la novela en una primera instancia sugiere que debiera tender hacia un proceso de investigación que responda a la finalidad del asesinato. La estrecha relación entre el establecimiento del enigma y la disposición estructural de cada una de las partes determina, por lo tanto, directamente el desenlace de la novela, donde se resuelve el porqué inicial. $\mathrm{O}$ al menos debiera hacerlo para ajustarse al canon policial. Esa rigidez intrínseca del género lleva a Todorov incluso a plantear que una marca característica del relato policial es su adecuación con las reglas que el mismo género le impone: "La novela policial por excelencia no es aquella que transgrede las reglas del género, sino la que se conforma a ellas" (2003: 64). Pero si contemplamos la relación que Bolaño establece entre el enigma y los indicios que mueven la investigación -y su posible resolución-, veremos que, en cambio, se da un progresivo desplazamiento y encubrimiento de la verdad del caso criminal.

La dependencia entre el enigma y la estructura de la novela, a la que hacíamos mención, influye en la disposición y elección de los indicios. De ahí que un método eficaz para la elaboración de una obra policial sea definir primeramente el enigma para luego organizar aquellos indicios por los que sería posible descubrirlo. Contemplada por el autor a la inversa del orden progresivo con que se narra, una novela de este tipo va mostrando solapadamente los indicios que llevan a la solución del enigma, como señala Román Gubern:

${ }^{8}$ Las otras dos formas del enigma policial apuntan al quién lo hizo (whodunit), si sólo se conoce el crimen y no el criminal, y al cómo lo hizo (howdunit), si el proceso de investigación parte del deseo por averiguar los mecanismos del crimen (Keating, 2003: 53-57). 
La 'arquitectura enigmática' de la novela policial ha impuesto a sus autores, como norma general, el que su intriga sea concebida a partir del final, de su solución. Partiendo de ella el autor desprende los datos o 'piezas informativas' que habrá de articular y dosificar en las etapas narrativas precedentes, cuidando que en ellas quede preservado siempre el misterio que sólo se develará en el último acto (1982: 14).

Aquellos indicios, huellas o pistas aparecen como una evidencia suficiente para llegar a la verdad del enigma, pero se esconden en el relato mismo y en el transcurso de la lectura. Esto, porque aunque contengan la información necesaria para descifrar el enigma, están dispuestos de manera dosificada junto a otros datos accidentales que perturban o confunden su lectura. Una lectura que así como está determinada por el poder paranoico de los signos, se comporta de manera análoga a la investigación emprendida por el detective: en ese acto de comparar, deducir y analizar se termina por proyectar el poder infinito de los signos para potencialmente revelar o encubrir el enigma (Barthes, 2003: 266). En ese intento por formular una hipótesis, por separar lo verdadero de lo falso, los indicios también cumplen la función de acelerar o retrasar la información, y es entonces cuando el rol subversivo de la digresión al momento de componer el relato cobra relieve, provocando un retraso sostenido en el movimiento hacia la revelación del enigma. De hecho, según la digresión implica un aplazamiento en el orden progresivo de la narración, su aparición en un relato policial supone también un alejamiento del camino hacia la revelación del enigma, y por eso debiera siempre estar subordinada a esa necesidad prácticamente ciega de que todas las partes, ya sea en la vertiente clásica o negra' ${ }^{9}$, guíen el transcurso del relato hacia esa revelación. Sin embargo, como supone una pausa en la secuencia temporal, tiende a prolongar indefinidamente el desvelamiento del enigma,

${ }^{9}$ Las formas más típicas de la vertiente clásica se definen con el nacimiento mismo del género y particularmente en el cuento "Los crímenes de la rue Morgue" (1841), de Edgar Allan Poe. Desde el punto de vista estructural, según Todorov lo propio del policial clásico es que se ordena sobre la base de dos historias: la del crimen, en que se presentan los datos ambiguos de un hecho delictivo; y la historia de la investigación, donde se da comienzo al análisis de los indicios y los sospechosos. En el policial negro -impulsado desde la década de los veinte en los Estados Unidos por la revista Black Mask-, en cambio, ambas historias se fusionan, de manera que prima el desarrollo de la investigación, y es allí donde se va configurando el enigma. Igualmente, en relación con el tiempo, Todorov agrega que en el relato clásico predomina el uso de la retrospección, mientras que en el negro, la prospección. Y, en relación con la lectura, en el policial clásico ésta se sostendría por la curiosidad (del efecto a la causa: de la aparición de un cadáver al encuentro del culpable, por ejemplo); y, en el negro, por el suspenso que, a la inversa, va de la causa al efecto (de la aparición de los malhechores al crimen) (2003: 67-70). 
de manera que lo que en un principio parecía ser la causa del desarrollo de la investigación termina convirtiéndose en un centro inaccesible que la narración sólo puede bordear; y, como consecuencia, los indicios pierden absolutamente su objetivo.

A pesar de que las digresiones pueden acrecentar el suspenso cuando actúan como interrupciones momentáneas -relativas a la descripción de personajes o del espacio- (Colmeiro, 1994: 78-79), siempre deben estar supeditadas a las reglas del género, y particularmente a la necesidad de que la sola lectura de los indicios permita resolver el enigma en la ficción (Van Dine, 1928 ${ }^{10}$. Esta idea de fair play, que refiere a la honestidad que el escritor le debe al lector, es trastocada por la digresión cuando se comporta como una estrategia que, constituyéndose en un aspecto distintivo para la composición de la novela, dilata sin término esa instancia donde se debe solucionar el misterio. Por lo tanto, desde el momento en que se encarga de suspender el tiempo de la narración, no sólo se opone al movimiento progresivo de la trama, sino que además añade tiempo extra:

Hence, a digression is a trick played on time. It is a way to deny linear time: temporally speaking there are only two directions (of which only one is practicable): a progression towards the future, and a regression towards the past. Digression is a third direction, a way to expand the present, to multiply it from within (Santovetti, 2007: 67) ${ }^{11}$.

Si en la máquina de la ficción policial la habilidad del autor estaría en mantener el equilibrio entre la fuerza progresiva -que avanza hacia la verdad de un enigma- y la digresiva -que desvía con falsas pistas ese camino-, en Estrella distante la preferencia de Bolaño por la segunda opción crea la ilusión de detener el tiempo, de delimitar una ficción donde el ocio forma parte constitutiva del relato. Es en esos espacios puestos en suspenso donde además surge la problemática entre ficción y realidad -los juegos autobiográficos entre los dobles que narran la novela, por ejemplo ${ }^{12}-$, que Sobejano

10 S.S. Van Dine en el artículo "Twenty Rules For Writing Detective Stories" (1928) postuló 20 reglas básicas del relato policial, que más tarde Todorov reformularía y reduciría a ocho en “Tipología del relato policial” (2003).

11 "Por lo tanto, la digresión es un truco con el tiempo. Es una manera de negar el tiempo lineal: temporalmente hablando hay sólo dos direcciones (de las cuales sólo una es practicable): la progresión hacia el futuro y la regresión hacia el pasado. La digresión es una tercera dirección, una forma de ampliar el presente, de multiplicarlo desde dentro". La traducción es mía.

${ }^{12}$ En los juegos de desdoblamiento de Bolaño narrador-personaje y Arturo B, personaje y coautor, los desvíos autorreferenciales sugieren una asimilación biográfica entre estas instancias, por 
apunta como consecuencia del particular manejo del tiempo en la novela digresiva: "no se hace notar como cronología ni como causalidad, sino en conexiones temáticas o prolongación de motivos, atravesando por las emersiones de la memoria involuntaria o por inmersiones en recuerdos obsesivos" (2005: 15). De este modo, en el desdoblamiento de un narrador que se propone recuperar el pasado siniestro, en el esfuerzo de la memoria por reconstruir la historia del crimen, se leen también las huellas de la digresión.

Así como el primer capítulo de Estrella distante es crucial para identificar el enigma que se configura en torno a la figura de Carlos Wieder, así también es un pilar fundamental que nos permite intuir, sin mayores certezas, la complejidad que éste irá adquiriendo, o bien, la disociación entre lo que en apariencia creemos que es el enigma y lo que efectivamente llegará a ser. Una comprensión más completa de la progresiva transformación del enigma de Carlos Wieder sólo se logra mediante la lectura retrospectiva de la novela. Sin embargo, desde un comienzo se divisa que hay algo más allá del simple asesinato de las Garmendia. A esto ayuda el uso de las cursivas en algunas palabras como recurso que intensifica la función del indicio. Por ejemplo, cuando el narrador describe la visita de Bibiano al departamento de Alberto Ruiz-Tagle en Concepción leemos: "tuvo la impresión de que la casa estaba preparada" (17). La narración, por lo demás, esquiva cualquier referencia a una finalidad. Ese para qué se omite y acrecienta el misterio en torno al enigma. Por otra parte, el suspenso se incrementa cuando Ruiz-Tagle, al abrir la puerta y ver a Bibiano, la vuelve rápidamente a cerrar, como si, según acota Bibiano, hubiese estado con una mujer y no quisiera ser descubierto. Una vez adentro, Bibiano sigue pensando que había alguien que escuchaba desde una habitación. Acotaciones como "el olor era espeso" o "lo único que sabía era que deseaba marcharse, decirle adiós a Ruiz-Tagle y no volver nunca más a aquella casa desnuda y sangrante" (18), funcionan también como indicios de los crímenes de las mujeres que posteriormente Carlos Wieder expondrá en las fotografías de 1974 en Santiago.

El criminal y el crimen, contenidos en la noción de enigma, ocultan en la novela una doble dimensión: aquella que propiamente se entiende dentro de los cánones del género policial como una pieza esencial que necesariamente

ejemplo, cuando leemos: "Por aquel entonces yo estaba internado en el Hospital Valle Hebrón de Barcelona con el hígado hecho polvo y me enteraba de sus triunfos, de sus chistes, de sus anécdotas, leyendo dos o tres periódicos diariamente" (85). Este uso del doble que tiende a desplazar la historia hacia las propias vivencias y reflexiones del narrador se podría relacionar con la dificultad para encarar el discurso sobre un horror prácticamente imposible de narrar. 
reclama el restablecimiento de la verdad dentro de la ficción ${ }^{13}$, y que de paso abre la posibilidad para su utilización subversiva; y la estética, una especie de valoración de la supuesta belleza del crimen o sublimación del mal, que termina por imponerse. Bajo el primer respecto, el crimen remite específicamente al asesinato de Angélica y Verónica Garmendia. El hecho ocurre en la casa de ellas, luego de una amena comida junto a la tía Ema Oyarzún y, el hasta entonces, Alberto Ruiz-Tagle, luego de discutir sobre poesía:

Y detrás de ellos entra la noche en la casa de las hermanas Garmendia. Y quince minutos después, tal vez diez, cuando se marchan, la noche vuelve a salir, de inmediato, entra la noche, sale la noche, efectiva y veloz. Y nunca se encontrarán los cadáveres, o sí, hay un cadáver, un solo cadáver que aparecerá años después en una fosa común, el de Angélica Garmendia (33).

La sorpresa del crimen abre un camino incierto tanto para la investigación como para la narración: desde entonces será el trayecto zigzagueante, confuso y netamente basado en conjeturas lo que marcará la historia de un crimen que pareciera no tener solución. Como un enigma al estilo clásico, a primera vista el asesinato de estas jóvenes poetas está despojado de una finalidad, al menos acorde a la lógica del crimen, que haga de aquel hecho algo esperable o sometido a la causalidad. Sólo queda la opción algo remota de que el crimen haya sido únicamente por causas políticas, que Ruiz-Tagle haya sido un infiltrado de la extrema derecha de aquellos años. De todas formas, la irracionalidad y el horror dominan la escena. Y a esto ayuda la omisión de una descripción acabada del asesinato. El narrador simplemente nos hace saber el hecho, pero no cómo Wieder mató a las hermanas, cómo ellas se defendieron o cómo quedaron sus cuerpos. Sólo está la metáfora de la noche y, a partir de allí, una narración digresiva incapaz de apegarse a la lógica del policial y que rodea esquivamente un enigma imposible tras el ahora llamado Carlos Wieder ${ }^{14}$. Únicamente hay acotaciones que revelan

${ }^{13}$ Esto marca la diferencia entre el género policial y la crónica periodística. En el primero, la verdad pertenece al orden discursivo del texto (la ficción narrada); mientras que en la segunda, la verdad está en el orden de lo real. Teniendo en cuenta el orden de verdad, la investigación policial en ambos géneros podrá ser fáctica (examen de lugares) o testimonial (examen de los testimonios en sus huecos, contradicciones, rectificaciones y aclaraciones) (Link, 2003: 138).

${ }^{14}$ Incluso si se repara en los significados de los nombres de las Garmendia se acentúa simbólicamente todavía más el acto de Carlos Wieder. Verónica (del latín Vero Icono), significa "la verdadera imagen de Jesús"; y, Angélica (del latín angelicus), "criatura angelical o parecida a los ángeles". Para un análisis más detallado de la figura femenina en los crímenes, véase "Ritual del bello crimen. Violencia femicida en Estrella distante" de Ainhoa Vásquez (2010). 
una percepción oculta que pareciera referir a algo inexpresable y que no pertenece al terreno de la certeza: "Otra vez era el Wieder de siempre, dominante, seguro, con los ojos como separados del cuerpo, como si miraran desde otro planeta" (93); o cuando recuerda el encuentro de la Gorda Posadas -también asistente al taller de Juan Stein- con Wieder: "Había sido, contra su voluntad, la confidente del diablo, pero estaba viva" (147).

Frente a este enigma incompleto, la narración rápidamente se desplaza hacia una investigación también carente de un objetivo preciso, y que se apoya sobre dos ejes: por una parte, la construcción de un perfil de Carlos Wieder y, por otra, su búsqueda real. La primera, que se desarrolla desde el capítulo uno hasta el penúltimo, se basa en los recuerdos que el narrador tiene de Carlos Wieder, el testimonio de su amigo Bibiano O'Ryan, las cartas que él le envía, diarios y revistas relacionadas con la obra poética de Wieder y un libro escrito por el teniente Julio César Muñoz Cano, titulado Con la soga al cuello. Cada una de estas fuentes arroja una serie de indicios que aportan al lector y al narrador -en la reconstrucción de ese pasado- una posible explicación a las motivaciones criminales de Wieder. Pero todo se reduce a un improvisado método que hace de la conjetura la única alternativa para al menos remotamente acercarse a su paradero ${ }^{15}$. Esta falta de certeza que rodea la investigación hace de la digresión una forma que del lado más político desafía no sólo al lector en la búsqueda de pistas, sino también al modelo convencional de relato policial. Esta herramienta, que Chambers entiende también como una "key device in the hands of practitioners of oppositionality" (1999: 86) ${ }^{16}$, por analogía resulta similar a la labor de Wieder como criminal y agitador cultural: así como la narración digresiva se opone a la estructuración dentro de un género cuyo principal motor es la revelación de un enigma, Wieder también a través de su arte criminal trastoca los valores y se rebela contra el orden institucional de un Chile sumergido en los horrores de la dictadura, del que este ex teniente de la Fuerza Aérea también es parte activa. En esas contradicciones se cifra la clave para comprender cómo la digresión, sobre todo en los capítulos posteriores, termina

${ }^{15}$ Nótese que uno de los recursos narrativos más usados por el narrador es el 'se dice que', lo que deja entrever que Wieder, al parecer, es un hombre conocido de la alta sociedad chilena o con un cierto grado de importancia dentro del panorama artístico. Y así el rumor es otra fuente de conocimiento que el narrador utiliza en su investigación: "Se dice que se ha vuelto rosacruz, que un grupo de seguidores de Joseph Peladan han intentado contactar con él, que una lectura en clave de ciertas páginas del Amphithéatre des sciences mortes preludia o profetiza su irrupción [...] Se dice que vive refugiado en el fundo de una mujer mayor que él, dedicado a la lectura y a la fotografía. Se dice que asiste de vez en cuando ( $\mathrm{y}$ sin avisar) al salón de Rebeca Vivar Vivanco" (107).

16 "Es una herramienta en manos de quienes practican la resistencia". La traducción es mía. 
por deformar la lógica policial.

Paralelamente a las indagaciones del narrador, Bibiano O'Ryan se sumerge de manera activa en la búsqueda de Wieder. Por el orden de las pistas en las que se centra su investigación y la seriedad de los resultados, Bibiano encarna más propiamente la figura del detective policial. La minuciosidad de su labor lo lleva a un viaje a Puerto Montt, al encuentro de la familia de Juan Stein, el profesor del taller de poesía en Concepción donde Wieder se habría iniciado en la literatura. Luego investiga a Diego Soto, enemigo de Stein; recorre los Archivos de la Biblioteca Nacional; viaja a California a contactar a Graham Greenwood, miembro de la Philip K. Dick Society, que postula una teoría sobre el mal; publica un artículo sobre los movimientos literarios fascistas, donde Wieder es la figura central; y, finalmente, envía a Abel Romero a continuar la investigación con la ayuda del narrador. Las andanzas de Bibiano, conocidas por las cartas que le envía al narrador, siguen una ruta más o menos lógica para encontrar a Wieder. Hay una metodología detrás que se vale del recuerdo, para desde ahí adentrarse en la búsqueda real. El peligro, por lo mismo, es una variable con la que Bibiano tiene que lidiar constantemente. $\mathrm{Y}$ ese peligro no es otra cosa que Wieder, una figura fantasmal inalcanzable, una presencia latente: una estrella distante. En una ocasión Bibiano incluso le confiesa al narrador que "su peor pesadilla es que Wieder, una noche cualquiera, lo encuentre a él” (106); por eso procurará "seguir la carrera de Wieder pero manteniéndose alejado, sin intentar nunca más una aproximación tan personal” (107).

Contrariamente a la labor del amateur, la aparición hacia el final de la novela de Abel Romero, el detective privado famoso por haber solucionado en veinticuatro horas un crimen en un cuarto cerrado ${ }^{17}$, abre una nueva perspectiva para la investigación: ¿cómo comprender a un artista criminal?, ¿qué motivaciones explican su desaparición? Y para acercarse a una respuesta necesita de la ayuda del narrador, una visión más alejada de lo racional, una mirada poética del crimen: "para encontrar a un poeta necesitaba la ayuda de otro poeta" (126). De manera similar a Dupin y al narrador de los cuen-

${ }^{17}$ El problema del cuarto cerrado, inicialmente planteado por Poe en "Los crímenes de la rue Morgue”, llegó a ser uno de enigmas más usados por los cultivadores del género. Básicamente consiste en un crimen cometido en una habitación cerrada por dentro, que debe ser resuelto sólo por medio del ingenio de la razón (Narcejac, 1982: 55). Uno de los mayores aciertos que demuestra la agudeza analítica de Romero -también personaje de Los detectives salvajes- es cuando le pide al narrador que vea unas películas pornográficas. Allí, dice, está Carlos Wieder. Tanto el narrador como el lector, ingenuamente, piensan que debe ser uno de los actores, pero Wieder, dice Romero, sería el fotógrafo de esas películas, un tal R. P. English, cuya historia reaparece en el cuento "Joanna Silvestri”, publicado en Llamadas telefónicas (1997). 
tos de Poe, cuando la investigación se daba por perdida, la dupla intentará reconstruir las piezas de un puzle que continuamente cambia de foco y que generalmente es atraído hacia las obsesiones del narrador. Un poeta que como detective aficionado define una nueva lógica investigativa, unida más al interés personal o al sentido de pertenecer a una generación -de suyo fragmentaria, olvidada, borrada de la historia de la literatura chilena- que al afán de hacer justicia. La diseminación de las huellas artísticas como consecuencia del contexto político constituye la premisa a partir de la cual se inicia el deseo de componer la imagen de Carlos Wieder, en una historia que adquiere tantas formas y desvíos como el escurridizo enigma.

El quiebre digresivo más notorio corresponde a las historias de Juan Stein y Diego Soto. Insertas como biografías en el capítulo cuatro y cinco, respectivamente, las andanzas de estos poetas, profesores de poesía en Concepción y desde siempre rivales, no sólo desplaza el relato policial hacia los márgenes de la historia, sino que también intensifica el misterio en torno a la inalcanzable figura de Wieder. A través del juego con los dobles, el narrador recoge los rastros discontinuos y opuestos de la vida de estos poetas desaparecidos, representativos, además, de una generación de artistas condenada al exilio. Desde una dualidad que sugiere quiebres interminables hacia otras historias dentro de la historia que se narra -la de Iván Cherniakovski en la de Juan Stein (60-62); la de Petra en la de Diego Soto (81-85)-, como en un juego de cajas chinas, Bolaño expande más allá de la ficción las infinitas posibilidades de una historia ya lejana del policial. Por medio de la digresión se inserta una historia dentro de otra, y así esta puesta en abismo nos entrega el reflejo o variación de otra historia (Dällenbach, 1991: 15-17), en un procedimiento lúdico que refuerza y amplía las dualidades que recorren Estrella distante.

La historia del enigma de Wieder, que por momentos puede ser leída como un intento de rescate de la vanguardia artística después del golpe de 1973 o como la reconstrucción alegórica del horror del período militar, se cifra también en el ambicioso proyecto artístico plasmado en los poemas escritos sobre el cielo y en la exposición de fotografías de mujeres asesinadas. Un Wieder inalcanzable sobrevuela Concepción y escribe en latín los versículos iniciales del Génesis, para luego terminar con un rotundo "APRENDAN" (39) y una seguidilla de crípticos versos que ensayan lo que para Wieder significaría una revolución del arte chileno -leemos, por ejemplo, en un revelador paréntesis: "(está a punto de nacer la <<nueva poesía chilena >>)" (83). Envuelto en un aire mesiánico, Wieder trastoca la verdad del crimen -la verdad del enigma, de él como culpable y fundamental para una lectura apegada al género- y la traslada a un plano artístico donde esa idea de verdad sigue 
funcionando de un modo perturbador, como si fuese algo frente a lo cual no quedase más que el miedo y el silencio ${ }^{18}$. Esta idea de subversión artística, en sintonía con lo que el propio Bolaño realiza en la novela, mueve a una lectura donde los principios de la vanguardia artística de izquierda se comportan como un trasfondo intertextual que ilumina el propósito destructor y renovador del proyecto de Wieder. En el Chile del llamado 'apagón cultural' de los primeros años de dictadura, dominado por la represión y la violencia, la apertura hacia nuevas formas discursivas y de representación tendría su referente en el arte de la Escena de Avanzada, un movimiento que para Nelly Richard "se constituyó después de 1977, y cuyo perfil más polémico se debió al radicalismo crítico de sus experimentaciones de lenguajes dirigidas vehementemente contra el sistema-arte" (1994: 37). En este conjunto de propuestas transgresoras y encaminadas a cuestionar los mecanismos de producción de la tradición artística, a través del cruce de géneros y soportes particularmente en el caso de la performance y la video-instalación-, se rescata el compromiso político del arte en la lucha contra el discurso hegemónico del estado autoritario ${ }^{19}$. Bolaño, por consiguiente, integra en el proyecto de Wieder una estética que, de la mano del compromiso político -amparado, en cambio, en la extrema derecha chilena-, toma prestada de esa Escena de Avanzada la experimentación transgresora y una poética de la violencia, que aplica tanto en sus poemas aéreos como en sus sádicas fotografías. Aquellos oscuros versos tienen como intertexto los poemas que Raúl Zurita ${ }^{20}$ dibujó en Nueva York en junio de 1982, cuyo registro fotográfico se incluye en Anteparaíso $(1982)^{21}$, un referente que a su vez ilumina el compromiso vital

${ }^{18}$ Una serie de intertextos van delineando el enigma: por ejemplo, la referencia a Moby Dick, cuando Wieder pilota la avioneta, resalta el estupor y la atracción que ejerce su figura $(54,55)$; a la película El bebé de Rosemary (1968), de Roman Polanski, agrega misterio y horror a la caracterización del departamento donde vivía Ruiz-Tagle (17); o al poema de Manuel Silva Acevedo, "Lobos y ovejas", cuando el narrador intenta descifrar los significados de la palabra Wieder, sugiere la idea de lo doble y el mal referidos a este personaje.

${ }^{19}$ Con un espíritu rupturista antidictatorial, la estética neovanguardista de la Escena de Avanzada se desarrolló en plástica (Carlos Leppe, Eugenio Dittborn, Juan Dávila, Carlos Altamirano, Lotty Rosenfeld, Alfredo Jaar, Catalina Parra, el grupo CADA) y literatura (Raúl Zurita, Diamela Eltit, Diego Maquieira, Juan Luis Martínez, Soledad Fariña). Véase: Arte en Chile desde 1973: escena de avanzada y sociedad de Nelly Richard (1997) (coord.); La estratificación de los márgenes de Nelly Richard (1989); y Campos minados. (Literatura post-golpe en Chile) de Eugenia Brito (1994).

${ }^{20}$ En el mismo Zurita se encierran las contradicciones de esos años: tal como Wieder recibe elogiosos comentarios de Ibacache (113-115), Zurita - pese a su militancia de izquierda-, es favorablemente criticado por Ignacio Valente (seudónimo de José Ibáñez Langlois), en el diario El Mercurio. En este crítico literario estará inspirado igualmente Sebastián Urrutia Lacroix, protagonista de Nocturno de Chile. Sobre la relación entre Wieder y Zurita, consúltese "Roberto Bolaño y Raúl Zurita: referencias cruzadas" de Chiara Bolognese (2010).

${ }^{21}$ El poeta chileno, autor de Purgatorio (1979), Canto a su amor desaparecido (1985) y La vida 
entre arte, política y vida que rodea el arte de Wieder, y que en sus fotografías se extenderá hasta la postvanguardia más radical -el Accionismo vienés, por ejemplo- (Manzi, 2005: 74; Jennerjahn, 2002: 75-79).

La utilización de la digresión en la novela implica la adopción de un estilo que transgrede el orden progresivo y convencional de una narración acorde a los criterios de mercado, y que para el género policial, como fenómeno íntimamente ligado a la industria y a la modernidad (Foucault, 1980: 90, 91), resulta fundamental. Según sostiene Damián Tabarovsky, en Literatura de izquierda (2004), ese polémico ensayo donde distingue la literatura comercial o escrita para el público de una que se propone cuestionar la idea de paradigma y orden literario - la literatura de izquierda, como le llama-, la digresión sería una forma de resistencia, un medio típicamente contracultural para componer la ficción:

Apunta a la trama para narrar su descomposición, para poner el sentido en suspenso: apunta al lenguaje para perforarlo, para buscar ese afuera-el afuera del lenguaje- que nunca llega, que siempre se posterga, se disgrega (la literatura como forma de digresión), ese afuera, o quizás ese adentro inalcanzable (16).

Esa dimensión crítica de la digresión, compartida por Chambers, se traduce en una apuesta vanguardista y contracultural que, movida por una fuerza similar al deseo, busca vulnerar un paradigma, en este caso el género, a través de la introducción de un desorden controlado (Chambers, 1999: 87), que aplaza indefinidamente el desenlace (Grohmann y Wells, 2010: 5): la verdad tras el enigma. Sin este requisito esencial, apunta Barthes, el policial se diluye por completo: “el 'retraso' causal no exaspera el crimen, sino que lo deshace: un crimen sin causa es un crimen que se olvida: el suceso desaparece" (2003: 265). De esta manera, como señala Ignacio Echevarría, la digresión se comportaría como un "agente de distorsión y de subversión de los discursos imperantes" (2005: 81), una marca del silencio y de los crímenes de la dictadura, que dibuja una zona impenetrable, emparentada además con la idea de secreto (Manzi, 2005: 72-79) y mal (Candia, 2010: 43-70), desde donde la ficción sobre Wieder queda sólo como un lejano reflejo del modelo policial.

nueva (1994), entre otros, y ganador en 2000 del Premio Nacional de Literatura, integró entre 1979 y 1985 el Colectivo de Acciones de Arte (CADA) -junto a Diamela Eltit, Juan Castillo, Lotty Rosenfeld y Fernando Balcells-, y llevaría a cabo transgresoras performances a través del uso del cuerpo como soporte artístico (Ortúzar, 2004: 107-113; Pellegrini, 2001: 41-64). 


\section{REFERENCIAS}

Barthes, Roland. 2003. Ensayos críticos. Buenos Aires: Seix Barral. . 2004. S/Z. Buenos Aires: Siglo XXI.

Bolaño, Roberto. 1993. La pista de hielo. Alcalá de Henares: Fundación Colegio del Rey. . 1996a. Estrella distante. Barcelona: Anagrama. . 1996b. La literatura nazi en América. Barcelona: Seix Barral. . 1997. Llamadas telefónicas. Barcelona: Anagrama. . 1998. Los detectives salvajes. Barcelona: Anagrama. . 1999. Monsieur Pain. Barcelona: Anagrama. 2000. Nocturno de Chile. Barcelona: Anagrama. 2004. 2666. Barcelona: Anagrama

Bolognese, Chiara. 2010. "Roberto Bolaño y Raúl Zurita: referencias cruzadas", en Anales de literatura chilena 14, pp. 259-272.

Brito, Eugenia. 1994. Campos minados. (Literatura post-golpe en Chile). Santiago: Cuarto Propio.

Candia, Alexis. 2010. "Todos los males el mal. La 'estética de la aniquilación' en la narrativa de Roberto Bolaño", en Revista Chilena de Literatura 76, pp. 47-70.

Chambers, Ross. 1971. "The Artist as Performing Dog”. Comparative Literature 4, pp. 312-324.

1993. "Messing around: gayness and loiterature in Alan Hollinghurst's The swimming-pool Library". En Textuality and Sexuality. Reading theories and practices, Judith Still \& Michael Worton (ed.). Manchester: Manchester University Press, pp. 207-217.

. 1994. "Strolling, Touring, Cruising: Counter-Disciplinary Narrative and the Loiterature of Travel". En Understanding Narrative, James Phelan y Peter J. Rabinowitz (ed.). Columbus: Ohio State, pp. 17-42.

. 1999. Loiterature. Lincoln: University of Nebraska Press.

. 2008. "On Inventing Unknownness. The Poetry of Disenchanted Reenchantment (Leopardi, Baudelaire, Rimbaud, Justice)", en French Forum 1-2, pp. 15-36.

Colmeiro, José. 1994. La novela policíaca española: teoría e historia crítica. Barcelona: Anthropos.

Dällenbach, Lucien. 1991. El relato especular. Madrid: Visor.

De Rosso, Ezequiel. 2002. "Una lectura conjetural. Roberto Bolaño y el relato policial". En Roberto Bolaño: la escritura como tauromaquia, Celina Manzoni (comp.). Buenos Aires: Corregidor, pp. 133-143. 
Echevarría, Ignacio. 2005. "Digresión y disidencia”. En La novela digresiva en España. El Puerto de Santa María: Bollullo, pp. 75-82.

Foucault, Michel. 1980. Microfísica del poder. Madrid: Ediciones de la Piqueta.

Grohmann, Alexis y Caragh Wells (ed.). 2010. Digressions in European Literature. From Cervante to Sebald. London: Palgrave Macmillan.

Gubern, Roman (comp.). 1982. La novela criminal. Barcelona: Tusquets.

Hoveyda, Fereydoun. 1967. Historia de la novela policíaca. Madrid: Alianza. Jennerjahn, Ina. 2002. "Escritos en los cielos y fotografías del infierno. Las 'Acciones de arte' de Carlos Ramírez Hoffman, según Roberto Bolaño", en Revista de Crítica Literaria Latinoamericana 56, pp. 69-86.

Keating, H.R.F. 2003. Escribir novela negra. Barcelona: Paidós.

Lafforgue, Jorge y Jorge Rivera. 1996. Asesinos de papel. Ensayos sobre narrativa policial. Buenos Aires: Colihue.

Link, Daniel. 2003. "La construcción de un caso: Cecilia Enriqueta Giubileo". En El juego de los cautos. Literatura policial: de Edgar A. Poe a P. D. James. Buenos Aires: La marca, pp. 134-139.

López Rivera, Juan Antonio. 2005. "La desautomatización del género policíaco en 'William Burns', de Roberto Bolaño”, en Tonos: Revista electrónica de estudios filológicos. (En línea). Disponible en http://www.um.es/ tonosdigital/znum9/corpora/RBO.htm. Consulta: 24/01/2011.

Manzi, Joaquín. 2005. "La proyección del secreto. Imagen y enigma en la obra de Roberto Bolaño". En Fernando Moreno (coord.), Roberto Bolaño. Una literatura infinita. Poitiers: Université de Poitiers-CNRS, pp. 69-86.

Manzoni, Cecilia (comp.). 2002. "Narrar lo inefable. El juego del doble y los desplazamientos en Estrella distante". En Roberto Bolaño: la escritura como tauromaquia. Buenos Aires: Corregidor, pp. 39-50.

Narcejac, Thomas. 1982. "Le roman policier". En Gubern, Roman (comp.), La novela criminal. Barcelona: Tusquets, p. 55.

Ortúzar, Macarena. 2004. "Anteparaíso de Raúl Zurita: una copia feliz del Edén”, en Hispamérica 98, pp. 107-113.

Pellegrini, Marcelo. 2001. "Poesía en/de transición: Raúl Zurita y La vida nueva", en Revista Chilena de Literatura 59, pp. 41-64.

Piglia, Ricardo. 2005. El último lector. Buenos Aires: Anagrama.

Pino, Mirian. 2006. "Bolaño y las relecturas de la novela negra: La pista de hielo", en Literatura y Lingüistica 17, pp. 117-128.

Quintiliano, M. F. 1799. Instituciones oratorias. Madrid: Imprenta Real. 
Richard, Nelly. 1989. La estratificación de los márgenes. Santiago: Francisco Zegers.

. 1994. La insubordinación de los signos: (cambio politico, transformaciones culturales y poéticas de la crisis). Santiago: Cuarto Propio.

. (coord.). 1997. Arte en Chile desde 1973: escena de avanzada y sociedad. Santiago: FLACSO.

Santovetti, Olivia. 2007. Digression. A narrative strategy in the Italian Novel. Bern: Peter Lang.

Sepúlveda, Magda. 2003. "La narrativa policial como género de la modernidad: La pista de Bolaño". En Patricia Espinosa (comp.), Territorios en fuga. Estudios críticos sobre Roberto Bolaño. Santiago: Frasis, pp. 103-115.

Simunovic, Horacio. 2006. "Estrella distante: crimen y poesía", en Acta literaria 33, pp. 9-25.

Sobejano, Gonzalo. 2005. "Adelantados de la novela discursiva: Luis Goytisolo, Miguel Espinosa, Juan Benet”, en La novela digresiva en España. El Puerto de Santa María: Bollullo, pp. 9-16.

Tabarovsky, Damián. 2004. Literatura de izquierda. Buenos Aires: Beatriz Viterbo Editora.

Todorov, Tzvetan. 2003. “Tipología del relato policial”. En Daniel Link (comp.), El juego de los cautos. Literatura policial: de Edgar A. Poe a P. D. James. Buenos Aires: La marca, pp. 67-70.

Tréllez Paz, Diego. 2005. "El lector como detective en la narrativa de Bolaño", en Fernando Moreno (coord.), Roberto Bolaño. Una literatura infinita. Poitiers: Université de Poitiers-CNRS, pp. 147-157.

Van Dine, S.S. 1928. "Twenty Rules For Writing Detective Stories", en The American Magazine, september.

Vásquez, Ainhoa. 2010. "Ritual del bello crimen. Violencia femicida en Estrella distante". En Felipe A. Ríos Baeza (ed.), Roberto Bolaño: ruptura y violencia en la literatura finisecular. México: Ediciones Eón, pp. 297-325.

Zurita, Raúl. 1979. Purgatorio. Santiago: Universitaria. . 1982. Anteparaíso. Santiago: Editores Asociados. . 1985. Canto a su amor desaparecido. Santiago: Universitaria. 1994. La vida nueva. Santiago: Universitaria. 